\title{
Pro-apoptotic versus anti-apoptotic properties of dietary resveratrol on tumoral and normal cardiac cells
}

\author{
Mauhamad Baarine $\cdot$ Sijo Joseph Thandapilly $\cdot$ Xavier Lieben Louis • \\ Frédéric Mazué $\cdot$ Liping Yu $\cdot$ Dominique Delmas $\cdot$ Thomas Netticadan • \\ Gérard Lizard • Norbert Latruffe
}

Received: 8 July 2010/Accepted: 21 April 2011/Published online: 4 May 2011

(C) Springer-Verlag 2011

\begin{abstract}
Resveratrol is a natural dietary polyphenol found in grape skin, red wine, and various other food products. Resveratrol has proved to be an effective chemopreventive agent for different malignant tumors. It has also been shown to prevent vascular alterations such as atherosclerosis and inflammatory-associated events. In view of these observations, we investigated the anti-proliferative and pro-apoptotic activities of resveratrol on a tumoral cardiac cell line (HL-1 NB) derived from mouse tumoral atrial cardiac myocytes. These effects were compared with those found on normal neonatal mouse cardiomyocytes. HL-1 NB cells and neonatal cardiomyocytes were treated with resveratrol $(5,30$, and/or $100 \mu \mathrm{M})$ for different times of culture (24, 48, and/or $72 \mathrm{~h})$. Resveratrol effects were determined by various microscopical and flow cytometric methods. After resveratrol treatment, a strong inhibition of tumoral cardiac HL1-NB cell growth associated with a loss of cell adhesion was observed. This cell proliferation arrest was associated with an apoptotic
\end{abstract}

The authors Mauhamad Baarine and Sijo Joseph Thandapilly have equally contributed to this work.

M. Baarine · F. Mazué · D. Delmas · G. Lizard ·

N. Latruffe (凹)

Centre de Recherche Inserm UMR 866 (Lipides, Nutrition, Cancer), Université de Bourgogne, Equipe Biochimie Métabolique et Nutritionnelle-6, Bd Gabriel, Dijon, France e-mail: latruffe@u-bourgogne.fr

S. J. Thandapilly $\cdot$ X. L. Louis · L. Yu - T. Netticadan Heart Failure Research Laboratory, Canadian Centre for Agri-Food Research in Health and Medicine, Manitoba, Canada

S. J. Thandapilly $\cdot$ X. L. Louis - T. Netticadan University of Manitoba, Winnipeg, MB, Canada process revealed by an increased percentage of cells with fragmented and/or condensed nuclei (characteristic of apoptotic cells) identified after staining with Hoechst 33342 and by the presence of cells in subG1. At the opposite, on normal cardiomyocytes, no cytotoxic effects of resveratrol were observed, and a protective effect of resveratrol against norepinephrine-induced apoptosis was found on normal cardiomyocytes. Altogether, the present data demonstrate that resveratrol (1) induces apoptosis of tumoral cardiac HL1-NB cells, (2) does not induce cell death on normal cardiomyocytes, and (3) prevents norepinephrine-induced apoptosis on normal cardiomyocytes.

Keywords Resveratrol - Apoptosis - Normal neonatal cardiomyocytes $\cdot$ HL1-NB cells

\section{Introduction}

Resveratrol (Rsv) is a dietary phytophenol and a strong anti-oxidant found predominantly in grapes and other berries (bilberries, blackberries, etc). This polyphenol exhibits numerous biological activities including prevention of oxidative stress which occurs in atherosclerosis and aging. Moreover, it also prevents cell proliferation and induces apoptosis in numerous tumor cells (Delmas et al. 2000; Latruffe et al. 2002; Delmas et al. 2002, 2003; Lançon et al. 2004; Jannin et al. 2004; Delmas et al. 2004, 2005, 2006; Lançon et al. 2007; Marel et al. 2008; Colin et al. 2008; Hanet et al. 2008; Colin et al. 2009). On the other hand, it has been shown that polyphenols (including Rsv) may have some benefits on heart functions (Dreger et al. 2008). Rsv is also able to upregulate peroxidedetoxifying mechanisms in cardiomyocytes as shown by its ability to protect these cells against hydrogen peroxide 
$\left(\mathrm{H}_{2} \mathrm{O}_{2}\right)$ (Mehendale et al. 2006) and doxorubicin-induced cell death (Du et al. 2007). Moreover, in cardiomyocytes, Rsv treatment led to a significant reduction in xanthine oxidase-induced intracellular accumulation of reactive oxygen species (ROS) (Du and Lou 2008). In addition, incubation of cardiac H9C2 cells with $25-100 \mu \mathrm{M}$ of Rsv resulted in a significant induction of cellular anti-oxidant enzymes in a concentration-dependent fashion (Cao and Li 2004). Furthermore, Rsv pretreatment also led to a marked reduction in xanthine oxidase/xanthine-induced intracellular ROS accumulation and cardiac cell apoptosis (Cao and Li 2004). These results on cells of the vascular wall (endothelial cells, smooth muscle cells, and macrophages) and on cardiac cells indicate that polyphenols, and particularly Rsv, could protect against cardiac cell apoptosis via the induction of endogenous anti-oxidant enzymes.

The development of pathological cardiac hypertrophy (abnormal enlargement of the heart) and apoptosis is associated with chronic activation of the $\beta$-adrenergic receptor signaling pathway as well as angiotensin II and endothelin-1 signaling cascades. In an in vitro study, we recently showed that Rsv prevents the development of pathological hypertrophy in heart muscle cells (cardiomyocytes) exposed to abnormal concentrations of norepinephrine (NE) (Louis et al. 2009). These results are consistent with in vivo studies from our laboratory which demonstrated that Rsv prevents the development of cardiac structural and functional abnormalities in two different animal models of hypertension (Juric et al. 2007; Thandapilly et al. 2010).

During apoptosis induced on various tumor cells, Rsv activates cell death by the mitochondrial intrinsic pathway or by the death receptor extrinsic pathway. We and others have showed that Rsv induces apoptosis in various tumor cell lines by modulating pro-apoptotic Bcl-2 family proteins behaving as sensors of cellular damage and initiating the agents of death process (Delmas et al. 2003). We have shown in colon cancer cells (Delmas et al. 2003) and others cells types that Rsv downregulates Bcl-2 protein expression (Billard et al. 2002) and gene expression which normally stabilizes the mitochondrial membrane potential and inhibits ROS production (Kaneuchi et al. 2003). In contrast to the downregulation of Bcl-2, Rsv has been shown to trigger an increase in Bax and Bak protein (Delmas et al. 2003; Jazirehi and Bonavida 2004) and gene expression (Kim et al. 2003). We showed that an exposure of adenocarcinoma colon cells to Rsv induces conformational changes, and mitochondrial redistribution of both Bax and Bak, suggesting that the two proteins are involved in Rsv-induced cell death (Delmas et al. 2003). We reported that Rsv-induced apoptosis by this mechanism involves the release of molecules such as cytochrome $\mathrm{c}$ and Smac/Diablo present in the mitochondrial inter-membrane space. The release of cytochrome $c$ in the cytosol induces oligomerization of the adapter molecule Apaf-1 to generate the apoptosome complex, in which caspase-9 is activated. Activated caspase-9 then triggers the catalytic maturation of caspase-3, thus leading to cell death. The release of Smac/Diablo (Delmas et al. 2003; Jazirehi and Bonavida 2004) neutralizes caspase inhibitors of the inhibitor of apoptotic proteins (IAP) family such as XIAP (Du et al. 2000). Rsv itself is able to inhibit IAP family protein expression such as survivin expression (Fulda and Debatin 2004). Rsv can also induce an increase in the tumor suppressor gene p53 in various cell types (Fulda and Debatin 2004) and lead to its phosphorylation (Haider et al. 2003). This activation of the transcription factor p53 by Rsv could contribute to death mechanism and cell cycle arrest (Huang et al. 1999). Meanwhile, Rsv can also induce apoptosis in p53-deficient cells (Mahyar-Roemer and Roemer 2001), indicating that p53 is not an absolute requirement for the cytotoxic effect of the molecule. In addition, Locatelli et al. also reported that Rsv inhibits human DNA polymerase involved in the $\mathrm{S}$ phase progression (Locatelli et al. 2005).

However, Rsv does not increase the expression of Fas and Fas ligand at the surface of tumor cells but induces a redistribution of Fas in the raft domains of the plasma membrane (Delmas et al. 2003). These lipid microdomains result from the preferential packing of complex sphingolipids and cholesterol in ordered plasma membrane structures and contain a variety of lipid-anchored and transmembrane proteins. Rafts play an important role in clustering or aggregating surface receptors, signaling enzymes, and adaptor molecules into membrane complexes at specific sites and were shown to be essential for initiating signaling from a number of receptors. Rsv induces a redistribution of Fas, together with FADD and procaspase8, in cholesterol and sphingolipids-enriched fractions (Delmas et al. 2003). Whatever the mechanisms, Rsvinduced redistribution of Fas in the rafts could contribute to the formation of the death-inducing signaling complex (DISC) observed in colon cancer cells treated with this compound (Delmas et al. 2004).

Despite many studies report the effectiveness of Rsv in several cancer models, no study has been performed to address the effect of Rsv on cardiac cells, especially on cardiac tumoral cells versus normal cardiac cells. Therefore, we undertook this study (1) to examine the effect of Rsv on mouse tumoral cardiac HL-1 NB cells versus normal neonatal mouse cardiomyocytes and (2) to bring additional in vitro evidences on the protective effect of Rsv on the cytotoxic effect of NE on normal cardiomyocytes (Deng et al. 2000; Juric et al. 2007; Thandapilly et al. 2010). 


\section{Experimental approaches}

\section{Reagents}

All chemicals were purchased from Sigma-Aldrich (Ontario, Canada) or from Sigma-Aldrich (Lyon, France).

Isolation and culture of neonatal mouse cardiomyocytes

Neonatal mouse primary cardiomyocytes were isolated from neonatal male C57BL/6 J mouse hearts as described by us previously (Sreejit et al. 2008). Briefly, 1-3 days old mice were killed by decapitation. Hearts were excised and transferred immediately into ice-cold phosphate-buffered saline (PBS). After the blood was gently squeezed out from the heart and washed with ice-cold PBS, the ventricles were excised into a petri dish. The tissue was then minced with sharp scissors and transferred to $50 \mathrm{ml}$ tubes. The tissues were then digested by incubating with $0.5 \%$ trypsin $-0.2 \%$ ethylenediamine tetraacetic acid (EDTA) at $37^{\circ} \mathrm{C}$ in a water bath for 4 min while mixed intermittently by pipetting. The cell suspension was allowed to stand for $1 \mathrm{~min}$. The supernatant containing single cells was transferred to another tube. A volume of $2 \mathrm{ml}$ of $20 \%$ fetal calf serum supplemented Dulbecco's modified Eagle's medium (DMEM) was then added. The digestion was repeated three times, and the cell suspensions from each digestion were pooled, centrifuged at $900 \mathrm{~g}$ for $10 \mathrm{~min}$ at $4^{\circ} \mathrm{C}$. The cell pellet was then resuspended in medium containing DMEM supplemented with fetal calf serum (20\%), horse serum (5\%), penicillin $(100 \mathrm{U} / \mathrm{ml})$, streptomycin $(100 \mathrm{mg} / \mathrm{ml}), 2 \mathrm{mM}$ L-glutamine, $0.1 \mathrm{mM}$ nonessential amino acids (Invitrogen, Ontario, Canada), $3 \mathrm{mM}$ sodium pyruvate, and bovine insulin $(1 \mu \mathrm{g} / \mathrm{ml})$. The cells were then maintained in $5 \% \mathrm{CO}_{2}$ incubator at $37^{\circ} \mathrm{C}$. Experimental procedures were initiated after $24 \mathrm{~h}$ of isolation.

\section{Culture of HL1-NB cells}

HL1-NB cells were a generous gift from Dr S Pelloux and Dr Y Tourneur (Centre Commun de Quantimétrie, Université of Lyon 1; Lyon, France) (Claycomb et al. 1998). The HL1-NB cells were derived from tumoral atrial cardiac myocytes from transgenic mice. HL1-NB cells were cultured in Claycomb medium supplemented with $10 \%$ fetal bovine serum, $4 \mathrm{mM}$ L-glutamine, $100 \mathrm{U} / \mathrm{ml}$ penicillin, $100 \mathrm{mg} / \mathrm{ml}$ streptomycin, $0.3 \mathrm{mM}$ ascorbic acid, and $10 \mathrm{mM}$ norepinephrine, at $37^{\circ} \mathrm{C}$ in a humid atmosphere of $5 \% \mathrm{CO} 2 / 95 \%$ air.

\section{Cell treatments}

To evaluate the pro- and anti-apoptotic effects of Rsv on tumoral mouse HL1-NB cells and on normal neonatal mouse cardiomyocytes, sub-confluent cultures were used. In agreement with previous investigations, Rsv was dissolved in ethanol, and the final concentration of ethanol in the culture medium did not exceed $0.1 \%$ (Delmas et al. 2003; Lançon et al. 2004; Jannin et al. 2004; Delmas et al. 2004, 2005; Lançon et al. 2007; Marel et al. 2008; Colin et al. 2008; Hanet et al. 2008; Colin et al. 2009). When the effects of Rsv were evaluated on norepinephrine (NE)-treated neonatal mouse cardiomyocytes, the following procedure was used: Rsv $(30 \mu \mathrm{M})$ was added on isolated neonatal mouse cardiomyocytes $30 \mathrm{~min}$ before to introduce $\mathrm{NE}(5 \mu \mathrm{M}$ in $15 \mathrm{mM}$ ascorbic acid), and the cells were simultaneously incubated with Rsv and NE for 24 and $48 \mathrm{~h}$.

\section{Phase contrast microscopy}

Phase contrast pictures were taken with a Zeiss LSM 5 Pascal microscope (Carl Zeiss MicroImaging, Inc., Thornwood, NY, USA). Based on morphological criteria, the pictures were used to determine the number of live cells in each group. Live cells are elongated, whereas dying cells are round.

\section{Hoechst staining procedure}

Cultured neonatal cardiomyocytes treated with and without Rsv and NE for 24 and $48 \mathrm{~h}$ or HL1-NB cells cultured for 48-72 h with Rsv were washed with PBS. Cells were then fixed with $2-4 \%$ paraformaldehyde diluted in PBS for 3 min and then washed with PBS. Cells were then stained with Hoechst $33342(1 \mu \mathrm{g} / \mathrm{ml}$ for $4 \mathrm{~min})$. After incubation, cells were washed 3 times with PBS, immediately viewed under a Zeiss LSM 5 Pascal fluorescent microscope, or mounted in Dako-Fluorescent medium (Dako, Copenhagen, Denmark), coversliped, and stored at $4{ }^{\circ} \mathrm{C}$ before observation with an Axioskop right microscope (Zeiss, Jena, Germany). Cells with condensed and/or fragmented nuclei, considered as apoptotic cells (Lizard et al. 1995), were identified and counted using captured fluorescent images.

\section{Flow cytometric analyses}

Apoptosis was determined by the proportion of cells in subG1, as previously described (Lizard et al. 1996), and by propidium iodide staining allowing distinguishing live and apoptotic cells (Lizard et al. 1995, 1996; Vermes et al. 1995; Elbim and Lizard 2009; Wlodkowic et al. 2008). To realize the staining procedure, adherent and nonadherent cells (collected by trypsinization with a $0.5 \%$ trypsin$0.2 \%$ EDTA solution) were pooled, washed with PBS, and $1 \times 10^{6}$ cells were stained with $5 \mu \mathrm{g} / \mathrm{ml}$ of propidium iodide (PI). Fluorescence PI was collected using a 
590/10 $\mathrm{nm}$ bandpass filter and was measured on a logarithmic scale. Flow cytometric analyses were performed on a Galaxy flow cytometer (Partec, Münster, Germany). For each sample, 10,000 cells were acquired and data analyzed with Flomax software (Partec).

\section{Statistical analysis}

Statistical analysis of data was performed by applying oneway analysis of variance (ANOVA) followed by Tukey post hoc test. Data were expressed as mean \pm standard error of the mean (SEM). Significance was defined as $P<0.05$.

\section{Results}

Induction of an apoptotic mode of cell death and accumulation of the cells in the $\mathrm{S}$ phase of the cell cycle in resveratrol-treated tumoral mouse cardiac HL1-NB cells

Tumoral mouse cardiac HL-1 NB cells were treated with 5-100 $\mu \mathrm{M}$ of Rsv for 48 and $72 \mathrm{~h}$, and microscopical and flow cytometric methods were used to evaluated Rsv activities.

In these conditions, the quantification of Rsv-induced cell death after staining with propidium iodide (PI) shows that at both 30 and $100 \mu \mathrm{M}, 50-70 \%$ of dead cells were found at 48 and $72 \mathrm{~h}$ in comparison with untreated cells (5-15\%) (Fig. 1a). Moreover, upon Rsv treatment, a strong inhibition of proliferation of HL1-NB cells associated with a loss of cell adhesion was observed (data not shown). This arrest of cell proliferation was associated with an apoptotic process revealed by an increased number of cells with fragmented and/or condensed nuclei identified after staining with Hoechst 33342 either at 48 or 72 h (Fig. 2). Thus, in untreated cells (control), there was around $2-5 \%$ of apoptotic cells after 48 and $72 \mathrm{~h}$ of culture; in contrast, the exposure to Rsv $(30 \mu \mathrm{M})$ raised the amount of apoptotic cells to $40 \%$ at $48 \mathrm{~h}$ and to $70 \%$ at $72 \mathrm{~h}$ (Fig. 1b). Whereas this effect seemed less marked with Rsv $(100 \mu \mathrm{M})$ incubated for $72 \mathrm{~h}$, numerous cells $(30-40 \%)$ in a probable secondary necrosis (corresponding to late apoptotic cells) were simultaneously observed. When the analysis of the cell cycle was performed by flow cytometry after staining with PI, Rsv increased in a dose-dependent manner and the percentage of cells in the subG1 phase known to only contain apoptotic cells (Wlodkowic et al. 2008) (Fig. 1c). In parallel, as previously reported on numerous tumoral cells (Marel et al. 2008; Colin et al. 2009), Rsv induces an important accumulation of HL1-NB cells in the S phase of the cell cycle (Fig. 1c).

\section{A Tumoral mouse cardiac HL1-NB cells}
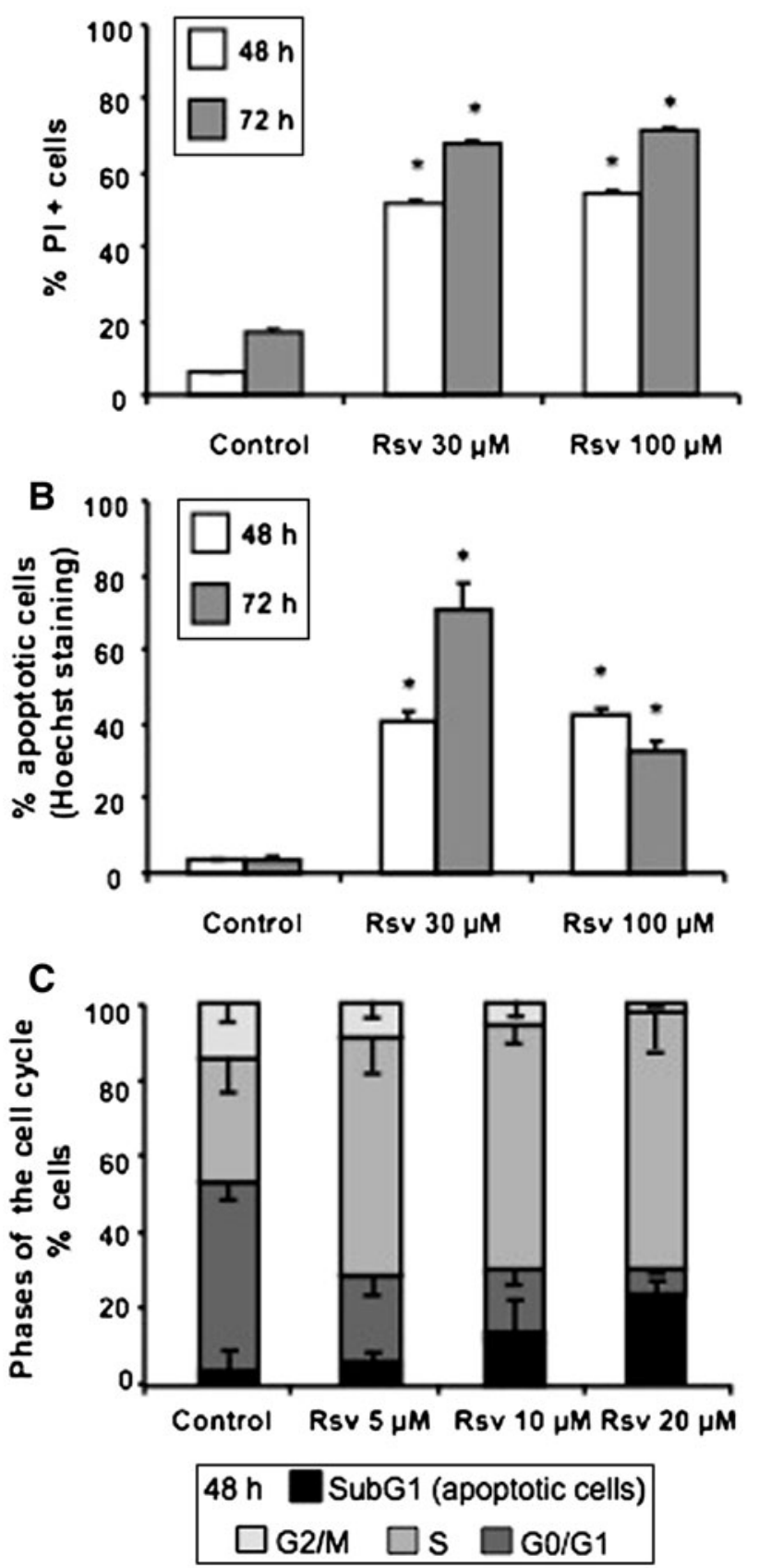

Fig. 1 Flow cytometric characterization of resveratrol-induced HL1NB cell death. Cell death induced by resveratrol (Rsv) on tumoral cardiac mouse HL1-NB cells was determined by various flow cytometric methods, a: Dead cells were characterized with propidium iodide (PI) staining, as it enters dead cells only, b: Hoechst 33342 staining was used to distinguish between normal and apoptotic cells (normal cells have round and regular nuclei whereas apoptotic cells have condensed and/or fragmented nuclei), c: PI was also used to analyze the proportion of the cells in different phases of the cell cycle (The subG1 peak contains only apoptotic cells). Data are representative of three independent experiments in triplicate, and presented as mean \pm SEM, $n=3$. Symbol denotes significance, $* P<0.05$ versus corresponding control 
Fig. 2 Induction of apoptosis on HL1-NB cells treated with resveratrol: analysis by fluorescence microscopy. Detection of apoptotic cells was performed by microscopical examination of nuclei after staining with Hoechst 33342 of tumoral cardiac mouse HL-1 $\mathrm{NB}$ cells cultured in the absence or in the presence of resveratrol (Rsv: $30 \mu \mathrm{M}$ ) for 48 and $72 \mathrm{~h}$. Normal cells have round and regular nuclei whereas apoptotic cells have condensed and/or fragmented nuclei
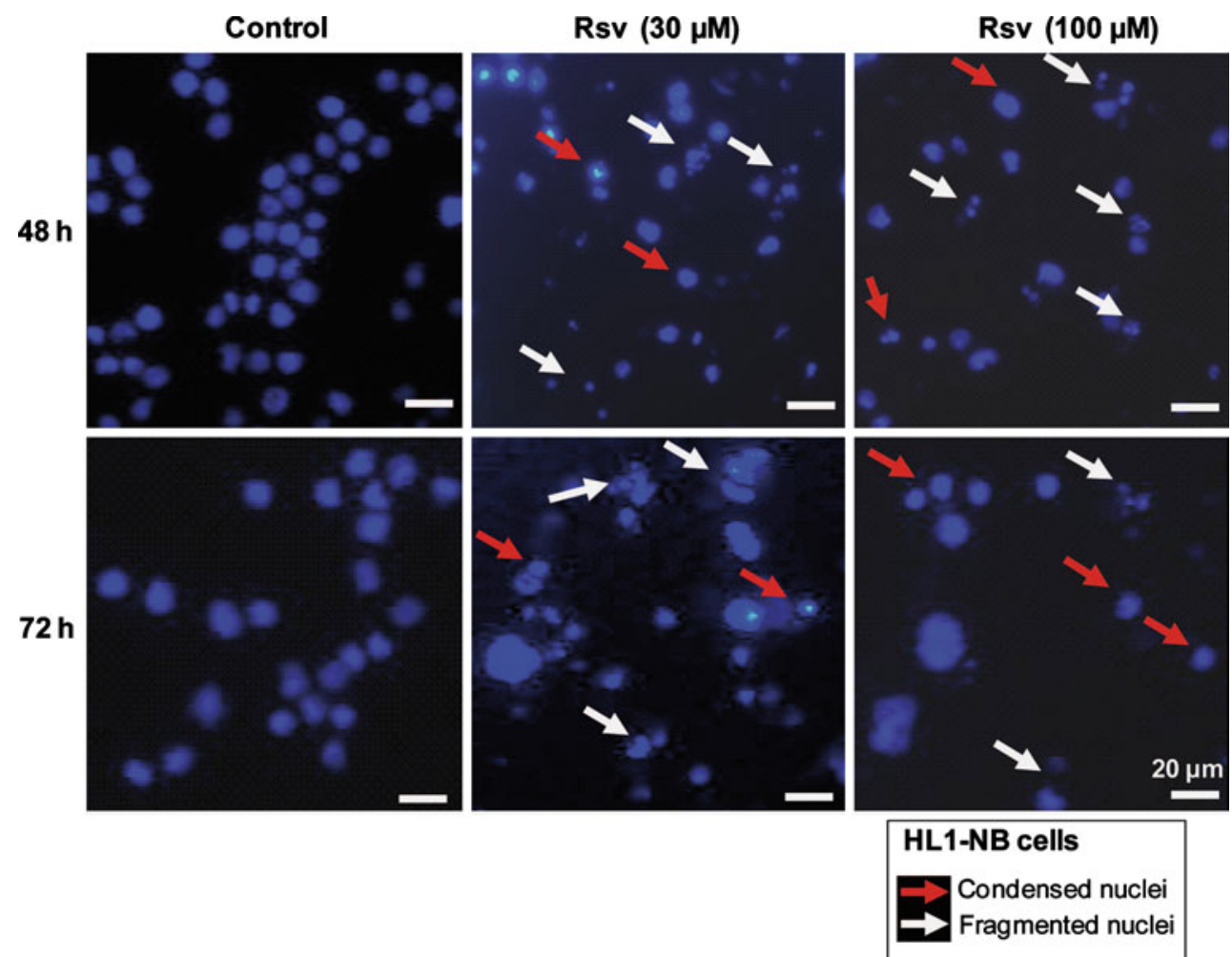

Protective effect of resveratrol on norepinephrinetreated neonatal mouse cardiomyocytes

Interestingly, when normal neonatal mouse cardiomyocytes were treated for $24 \mathrm{~h}$ with NE $(5 \mu \mathrm{M})$, we found that co-treatment with Rsv used at $30 \mu \mathrm{M}$ protects normal neonatal mouse cardiomyocytes from NE-induced cell death (Fig. 3a). Whereas elongated cells (corresponding to healthy cells) were observed in untreated cells (control), some round cells (corresponding to dying cells) were observed when normal neonatal mouse cardiomyocytes were exposed to NE. Interestingly, the treatment of NE-exposed normal neonatal cardiomyocytes with Rsv $(30 \mu \mathrm{M})$ prevented from NE-induced cell death. The quantification of the protective effect of Rsv against NE-induced cell death is reported in Fig. 3a. In addition, no cytotoxic effects were observed on Rsv (30 $\mu \mathrm{M})$-treated normal cardiomyocytes (Fig. 3b).

In the same experimental conditions, when normal neonatal mouse cardiomyocytes were stained with Hoechst 33342, we observed that NE induced an apoptotic mode of cell death on normal cardiomyocytes and that this mode of cell death was strongly counteracted by Rsv (Fig. 4a, b).

\section{Discussion}

Primary cardiac tumors are rare clinical entities, and these malignant tumors are hardly resectable. The long-term diagnosis for resected benign cardiac tumors is excellent whereas it is very poor for cardiac sarcomas. For patients with unresectable cardiac sarcomas, radiation and chemotherapy may be used, but without great expectation of successful results, mainly due to anti-cancer drug toxicities. Therefore, in the present study, we tested the ability of Rsv to specifically induce cell death of tumoral cardiac cells without being toxic to normal cardiomyocytes. Indeed, whereas Rsv has proved to be an effective chemopreventive agent for different malignant tumors (Delmas et al. 2006) and contributes to prevent vascular alterations such as atherosclerosis and inflammation (Delmas et al. 2005), little is known on the activity of Rsv on normal cells. Therefore, in the present study, we investigated the pro-apoptotic activities of Rsv on a tumoral cardiac cell line, HL-1 NB, derived from the AT-1 mouse atrial cardiomyocyte tumor lineage (Claycomb et al. 1998), as well as on normal cardiomyocytes isolated from neonatal mice (Sreejit et al. 2008). In this context, we treated tumoral cardiac HL-1 NB cells and normal cardiomyocytes, with 5,30 and/or- $100 \mu \mathrm{M}$ of Rsv at different time points (24, 48 and/or $72 \mathrm{~h}$ ), and Rsv activities were determined by microscopical and flow cytometric methods. In addition, we attempted to bring additional in vitro evidences on the protective effect of Rsv on the cytotoxic effect of NE on normal cardiomyocytes (Deng et al. 2000; Juric et al. 2007; Thandapilly et al. 2010).

Noteworthy, upon Rsv treatment, a strong inhibition of tumoral cardiac cell growth associated with a loss of cell 

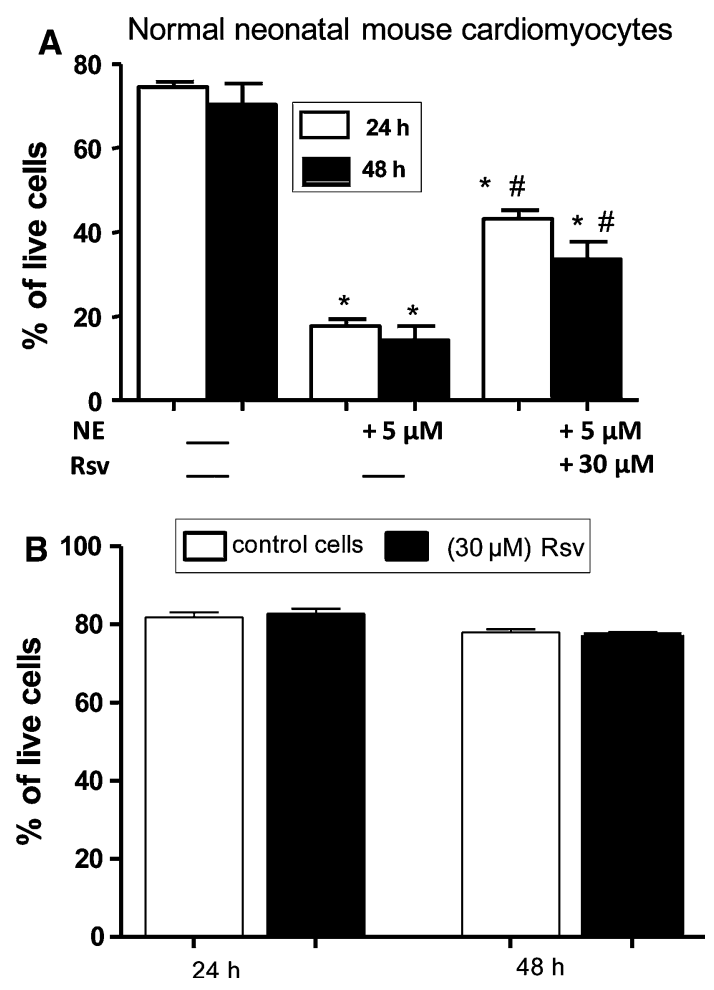

Fig. 3 Protective effect of resveratrol on norepinephrine-induced normal neonatal cardiomyocytes cell death. a: Protective effect of $30 \mu \mathrm{M}$ resveratrol (Rsv) on norepinephrine (NE: $5 \mu \mathrm{M}$ )-induced cell death on normal neonatal mouse cardiomyocytes: some round cells characteristic of dying cells were observed by phase contrast microscopy under treatment with $\mathrm{NE}$, which was significantly prevented with resveratrol pre-treatment. Data presented are means \pm SEM, $n=3$. ${ }^{*} P<0.05$ versus control; \# $P<0.05$ versus $\mathrm{NE}$. b: In the presence of $30 \mu \mathrm{M}$ of resveratrol (Rsv), no cytotoxic effects (presence of round cells) were observed by phase contrast microscopy on normal neonatal cardiomyocytes. Data are means of three independent experiments; each experiment was done in triplicate. Data presented are means $\pm \mathrm{SEM}, n=3$

adhesion was observed, associated with an apoptotic process revealed by an increased number of cells with fragmented and/or condensed nuclei identified (characteristic of apoptotically dying cells) (Lizard et al. 1995) after staining with Hoechst 33342. Altogether, these different criteria support that Rsv might induce a particular mode of cell death by apoptosis on tumoral cardiac cells: anoikis (Valentijn et al. 2004). Indeed, anoikis is a form of programmed cell death. It is induced by detaching the anchorage-dependent cells from the extracellular matrix (Valentijn et al. 2004). It has been reported on glioma cells that integrin (which are receptors mediating cell attachment with other cells or the extracellular matrix) are implied in Rsv-induced apoptosis (Lin et al. 2008). Moreover, as some HL1-NB cells are permeable to PI when they are treated with Rsv, these data support that Rsv-induced cell death is a dynamic process involving apoptosis and probable secondary necrosis (Challa and Chan 2010). When cell cycle analysis was performed by flow cytometry after staining with PI, data obtained on Rsv-treated cells also permit to reveal a subG1 peak that constitutes additional criteria of apoptotically dying cells. Indeed, by using cell sorting, these subG1 peaks have been shown to only contain apoptotic cells (Ormerod et al. 1992). In parallel, in agreement with data obtained in our laboratory on tumoral cells (Marel et al. 2008; Colin et al. 2009), Rsv-induced apoptosis is associated with an important accumulation of HL1-NB cells in the S phase of the cell cycle, underlying that the effect of Rsv on the cell cycle does not depend on the cell type considered.

On another hand, the effects of Rsv on NE-treated normal neonatal cardiomyocytes were also studied. NE (also named noradrenaline) is a catecholamine synthesized from dopamine by dopamine $\beta$-hydroxylase. It is released from the adrenal medulla into the blood as a hormone and is also a neurotransmitter in the central nervous system and sympathetic nervous system where it is released from noradrenergic neurons. The actions of NE are carried out via the binding to adrenergic receptors. In intensive care units, NE is used to provide hemodynamic support and maintain organ perfusion (Maeder et al. 2006; Di Giantomasso et al. 2005). However, a major side effect of this molecule is to induce apoptosis on normal cardiomyocytes (Singh et al. 2001). It is now well admitted that NE binds to $\beta 1$ - and $\alpha 1$-adrenergic receptor mainly in cardiac myocytes and that $\beta 1$-adrenergic stimulation induces caspase-3dependent apoptosis on myocardial cells through Gs protein that stimulates adenylyl cyclase activity, leading to the production of cAMP, followed by the activation of protein kinase A (Iwai-Kanai and Hasegawa 2004). Based on these considerations, molecules capable to inhibit NE-induced apoptosis have therefore important pharmacological interests. Interestingly, when normal neonatal cardiomyocytes were treated with NE, we observed that Rsv protects these cells from cell death. Our finding, which establishes that Rsv is capable to reduce NE-induced apoptosis, may consequently have some pharmacological applications since endothelin 1 or NE induced apoptosis on cardiomyocytes, can contribute in the deterioration of systolic function during the development of heart failure in vivo (Iwai-Kanai and Hasegawa 2004). Therefore, as no cytotoxic activities of polyphenols are suspected on cardiac cells and as no induction of cell death were observed in the present investigation on Rsv-treated normal cardiomyocytes, it is tempting to speculate that Rsv, and certain Rsv derivatives, might constitute a possible new class of therapeutic agents capable to target and counteract apoptosis on normal cardiomyocytes.

In conclusion, data obtained on cardiac tumoral HL1NB cells and normal neonatal cardiomyocytes permitted to demonstrate a dual effect of Rsv depending on the cell type 
Fig. 4 Effect of resveratrol on neonatal cardiomyocytes apoptosis. a: Protective effect of $30 \mu \mathrm{M}$ resveratrol (Rsv) on norepinephrine (NE: $5 \mu \mathrm{M}$ )induced apoptosis in normal neonatal mouse

cardiomyocytes. a: Apoptotic cells (characterized by condensed and/or fragmented nuclei) were identified and counted using fluorescent images of four independent regions from the same culture dish. Data presented are means \pm SEM, $n=3$.

* $P<0.05$ versus control; $\# P<0.05$ versus NE. $\mathbf{b}$ : Representative Hoechst 33342 staining microscopic pictures showing the effect of Rsv on NE-induced apoptosis;

(a) untreated normal neonatal cardiomyocytes (control);

(b) normal neonatal cardiomyocytes with $(5 \mu \mathrm{M})$ $\mathrm{NE}$; (c) normal neonatal cardiomyocytes with $(5 \mu \mathrm{M})$ $\mathrm{NE}$ and $(30 \mu \mathrm{M}) \mathrm{Rsv}$;

(d) normal neonatal cardiomyocytes with $(30 \mu \mathrm{M})$ Rsv

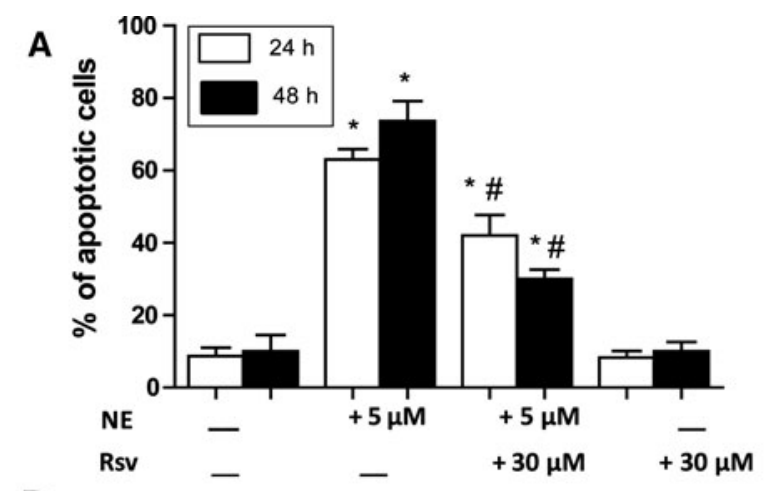

B
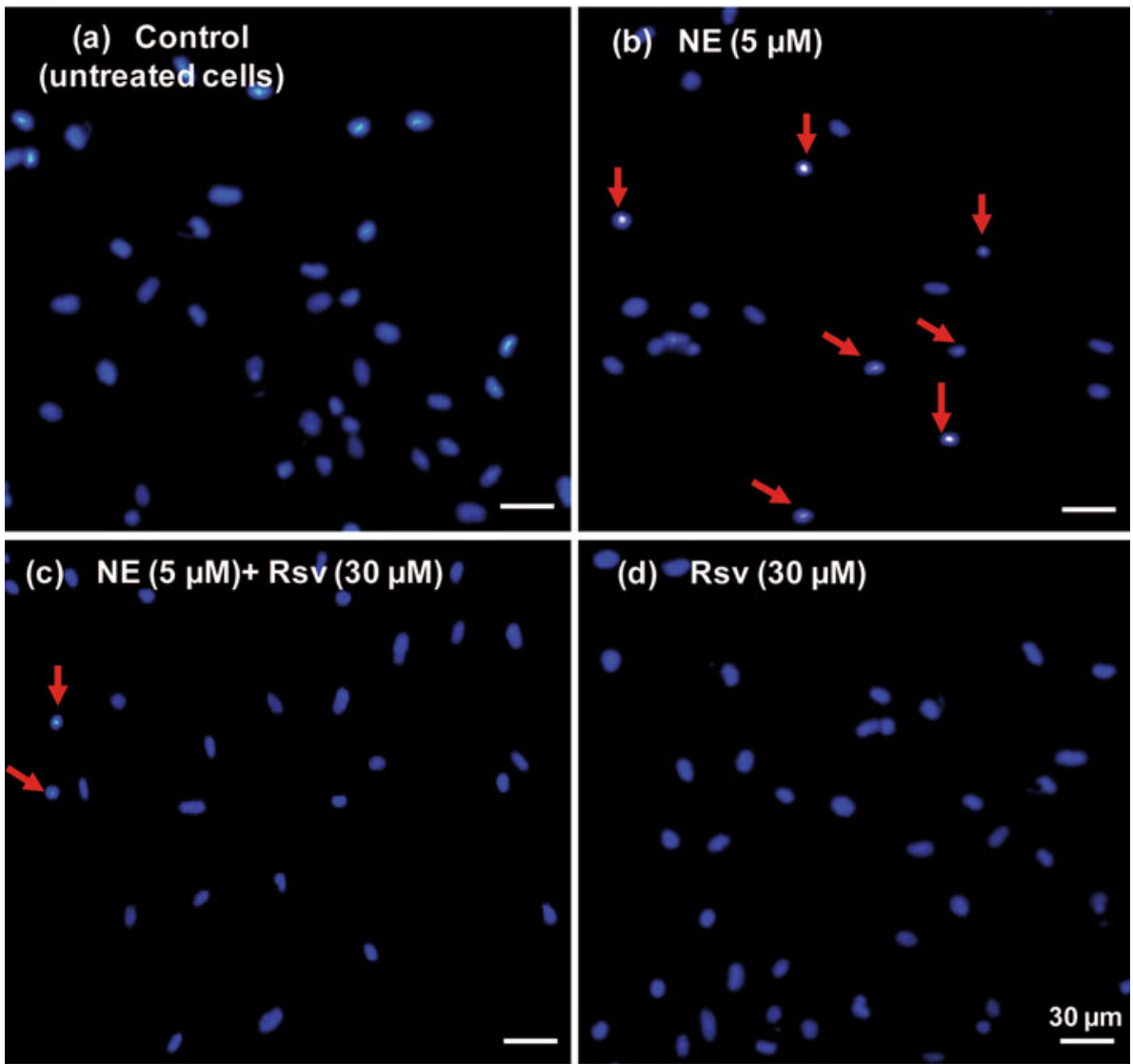

Normal neonatal cardiomyocytes (48 h)

Condensed nuclei considered, i.e., tumoral versus normal cells. Thus, on tumoral HL1-NB cells, in agreement with data obtained on various tumor cells (Delmas et al. 2006; Billard et al. 2002), Rsv is a potent inducer of apoptosis associated with an accumulation of the cells in the $S$ phase of the cell cycle, whereas on normal neonatal cardiomyocytes Rsv does not induce cell death. Moreover, as Rsv is capable to counteract NE-induced apoptosis, this observation may lead to the development of new drugs capable to reduce the cardiac toxicity of NE which is widely used molecule in intensive care units to provide hemodynamic support and maintain organ perfusion (Maeder et al. 2006; Di Giantomasso et al. 2005). In addition, this work opens new perspectives to further investigate the basis of the mechanisms associated with the protective and cytotoxic effects of Rsv on normal and tumoral cardiac cells and to better understand the connections between these two processes. We recently identified new signaling pathways involving the modulation of pro-oncogenic miRNAs in promonocytic tumoral cells and colon tumor cells (Tili et al. 2010a, b). 
The determination of the part taken by miRNAs in Rsv sensitivity can have some pharmacological interests to improve Rsv efficiency in various major diseases such as cardiovascular diseases and cancers. Indeed, very recently, it has been reported that resveratrol restores the expression of some altered micro-RNA in the ischemic rat heart (Mukhopadhyay et al. 2010). Moreover, the present data also support our objectives to develop nutraceutical and functional foods based on dietary Rsv with the aim to prevent or reverse cardiac dysfunctions and diseases.

Acknowledgments French Cancer League, Regional Council of Burgundy, Jura and Nièvre Cancer Leagues, BIVB, Heart and Stroke Foundation of Manitoba, Canada, operating grant to Dr. Thomas Netticadan.

\section{References}

Billard C, Izard JC, Roman V, Kern C, Mathiot C, Mentz F, Kolb JP (2002) Comparative anti-proliferative and apoptotic effects of resveratrol, epsilon-viniferin and vine shots derived polyphenols (vineatrols) on chronic B lymphocytic leukemia cells and normal human lymphocytes. Leuk Lymphoma 43:1991-2002

Cao Z, Li Y (2004) Potent induction of cellular antioxidants and phase 2 enzymes by resveratrol in cardiomyocytes: protection against oxidative and electrophilic injury. Eur $\mathrm{J}$ Pharmacol 489:39-48

Challa S, Chan FK (2010) Going up in flames: necrotic cell injury and inflammatory diseases. Cell Mol Life Sci 67:3241-3253

Claycomb WC, Lanson NA Jr, Stallworth BS, Egeland DB, Delcarpio JB, Bahinski A, Izzo NJ Jr (1998) HL-1 NB cells: a cardiac muscle cell line that contracts and retains phenotypic characteristics of the adult cardiomyocyte. Proc Natl Acad Sci USA 95:2979-2984

Colin D, Lançon A, Delmas D, Abrassimow J, Jannin B, Lizard G, Kahn E, Latruffe N (2008) Comparative study of the cell uptake and the antiproliferative effects of resveratrol, epsilon-viniferin and their acetates. Biochimie 90:1674-1684

Colin D, Gimazane A, Lizard G, Izard JC, Solary E, Latruffe N, Delmas D (2009) Resveratrol analogues compounds-induced early S phase arrest through specific Cdk/cyclin complex which leads to a higher sensitization of human colon cancer cells to 5-FU. Int J Cancer 124:2780-2788

Delmas D, Jannin B, Cherkaoui-Malki M, Latruffe N (2000) Inhibitory effect of resveratrol on the of human and rat hepatic derived cell lines. Oncol Rep 7:847-852

Delmas D, Passilly-Degrace P, Jannin B, Cherkaoui-Malki M, Latruffe N (2002) Resveratrol, a chemopreventive agent, disrupts the cell cycle control of human SW480 colorectal tumor cells. Int J Mol Med 10:193-199

Delmas D, Rebe C, Lacour S, Filomenko R, Athias A, Gambert P, Cherkaoui-Malki M, Jannin B, Dubrez-Daloz L, Latruffe N, Solary E (2003) Resveratrol-induced apoptosis is associated with Fas redistribution in the rafts and the formation of a death inducing signaling complex in colon cancer cells. J Biol Chem 278:41482-41490

Delmas D, Rébé C, Micheau O, Athias A, Gambert PH, Grazide S, Laurent G, Latruffe N, Solary E (2004) Redistribution of CD95, DR4 and DR5 in rafts accounts for the synergistic toxicity of resveratrol and death receptors ligands in colon carcinoma cells. Oncogene 23:8979-8986
Delmas D, Jannin B, Latruffe N (2005) Resveratrol: preventing properties against vascular alterations and ageing. Mol Nut Food Res 49:377-395

Delmas D, Lancon A, Colin D, Jannin B, Latruffe N (2006) Resveratrol as chemopreventive agent: new concepts to put forward the molecule to fight cancer. Curr Drug Targets $7: 423-442$

Deng XF, Rokosh DG, Simpson PC (2000) Autonomous and growth factor-induced hypertrophy in cultured neonatal mouse cardiac myocytes. Comparison with rat. Circ Res 87:781-788

Di Giantomasso D, Bellomo R, May CN (2005) The haemodynamic and metabolic effects of epinephrine in experimental hyperdynamic septic shock. Intensive Care Med 31:454-462

Dreger H, Lorenz M, Kehrer A, Baumann G, Stangl K, Stangl V (2008) Characteristics of catechin- and theaflavin-mediated cardioprotection. Exp Biol Med 233:427-433

Du Y, Lou H (2008) Catechin and proanthocyanidin B4 from grape seeds prevent doxorubicin-induced toxicity in cardiomyocytes. Eur J Pharmacol 591:96-101

Du C, Fang M, Li Y, Li L, Wang X (2000) Smac, a mitochondrial protein that promotes cytochrome c-dependent caspase activation by eliminating IAP inhibition. Cell 102:33-42

Du Y, Guo H, Lou H (2007) Grape seed polyphenols protect cardiac cells from apoptosis via induction of endogenous antioxidant enzymes. J Agric Food Chem 55:1695-1701

Elbim C, Lizard G (2009) Flow cytometric investigation of neutrophil oxidative burst and apoptosis in physiological and pathological situations. Cytometry A 75:475-481

Fulda S, Debatin KM (2004a) Sensitization for tumor necrosis factorrelated apoptosis inducing ligand-induced apoptosis by the chemopreventive agent resveratrol. Cancer Res 6:337-346

Fulda S, Debatin KM (2004b) Sensitization for anticancer druginduced apoptosis by the chemopreventive agent resveratrol. Oncogene 23:6702-6711

Haider UG, Sorescu D, Griendling KK, Vollmar AM, Dirsch VM (2003) Resveratrol increases serine15-phosphorylated but transcriptionally impaired p53 and induces a reversible DNA replication block in serum-activated vascular smooth muscle cells. Mol Pharmacol 63:925-932

Hanet N, Lançon A, Heydel JM, Jannin B, Delmas D, Chagnon MC, Cherkaoui Malki M, Latruffe N, Artur Y (2008) Endocrine disruptors affect 17b-estradiol cellular bioavailability and the expression of proteins involved in the hormone metabolism and exretion in HepG2. Steroids 73:1242-1251

Huang C, Ma WY, Goranson A, Dong Z (1999) Resveratrol suppresses cell transformation and induces apoptosis through a p53-dependent pathway. Carcinogenesis 20:237-242

Iwai-Kanai E, Hasegawa K (2004) Intracellular signaling pathways for norepinephrine- and endothelin-1-mediated regulation of myocardial cell apoptosis. Mol Cell Biochem 259:163-168

Jannin B, Menzel M, Berlot JP, Delmas D, Lançon A, Latruffe N (2004) Transport of resveratrol, a cancer chemopreventive agent, to cellular targets, plasmatic protein binding and cell uptake. Biochem Pharmacol 68:1113-1118

Jazirehi AR, Bonavida B (2004) Resveratrol modifies the expression of apoptotic regulatory proteins and sensitizes non-Hodgkin's lymphoma and multiple myeloma cell lines to paclitaxel-induced apoptosis. Mol Cancer Ther 3:71-84

Juric D, Wojciechowski P, Das DK, Netticadan T (2007) Prevention of concentric hypertrophy and diastolic impairment in aorticbanded rats treated with resveratrol. Am J Physiol Heart Circ Physiol 292:H2138-H2143

Kaneuchi M, Sasaki M, Tanaka Y, Yamamoto R, Sakuragi N, Dahiya $\mathrm{R}$ (2003) Resveratrol suppresses growth of Ishikawa cells through down-regulation of EGF. Int J Oncol 23:1167-1172 
Kim YA, Rhee SH, Park KY, Choi YH (2003) Antiproliferative effect of resveratrol in human prostate carcinoma cells. J Med Food 6:273-280

Lançon A, Delmas D, Osman H, Thénot JP, Jannin B, Latruffe N (2004) Human hepatic cell uptake of resveratrol: involvement of both passive diffusion and carrier-mediated process. Biochem Biophys Res Commun 316:1132-1137

Lançon A, Hanet N, Jannin B, Delmas D, Heydel JM, Lizard G, Chagnon MC, Artur Y, Latruffe N (2007) Resveratrol in human hepatoma HepG2 cells: metabolism and inducibility of detoxifying enzymes. Drug Metab. Dispos 35:699-703

Latruffe N, Delmas D, Jannin B, Cherkaoui-Malki M, PassillyDegrace P, Berlot JP (2002) Molecular analysis on the chemopreventive properties of resveratrol, a plant polyphenol microcomponent. Int J Mol Med 10:755-760

Lin HY, Tang HY, Keating T, Wu YH, Shih A, Hammond D, Sun M, Hercbergs A, Davis FB, Davis PJ (2008) Resveratrol is proapoptotic and thyroid hormone is anti-apoptotic in glioma cells: both actions are integrin and ERK mediated. Carcinogenesis 29:62-69

Lizard G, Fournel S, Genestier L, Dhedin N, Chaput C, Flacher M, Mutin M, Panaye G, Revillard JP (1995) Kinetics of plasma membrane and mitochondrial alterations in cells undergoing apoptosis. Cytometry 2:275-283

Lizard G, Deckert V, Dubrez L, Moisant M, Gambert P, Lagrost L (1996) Induction of apoptosis in endothelial cells treated with cholesterol oxides. Am J Pathol 148:1625-1638

Locatelli GA, Savio M, Forti L, Shevelev I, Ramadan K, Stivala LA, Vannini V, Hübscher U, Spadari S, Maga G (2005) Inhibition of mammalian DNA polymerases by resveratrol: mechanism and structural determinants. Biochem J 389:259-268

Louis XL, Thandapilly SJ, Yu L, Wojciechowski P, Yang T, Stringer DM, Douville JM, Cheung DYC, Massaeli H, Zhang S, Wigle J, Kardami E, Zahradka P, Netticadan T (2009). Resveratrol prevents norepinephrine induced hypertrophy in adult cardiomyocytes. Proceedings of the 6th Meeting of the Canadian oxidative stress consortium, p 100

Maeder M, Fehr T, Rickli H, Ammann P (2006) Sepsis-associated myocardial dysfunction, diagnostic and prognostic impact of cardiac troponins and natriuretic peptides. Chest 129:1349-1366

Mahyar-Roemer M, Roemer K (2001) p21 Waf1/Cip1 can protect human colon carcinoma cells against p53-dependent and p53independent apoptosis induced by natural chemopreventive and therapeutic agents. Oncogene 20:3387-3398

Marel AC, Lizard G, Izard JC, Latruffe N, Delmas D (2008) Effect of resveratrol derived molecules on the proliferation and the cell cycle progression of human tumoral cells. Mol Nut Fd Res 52:538-548

Mehendale SR, Wang CZ, Shao ZH, Li CQ, Xie JT, Aung HH, Yuan CS (2006) Chronic pretreatment with American ginseng berry and its polyphenolic constituents attenuate oxidant stress in cardiomyocytes. Eur J Pharmacol 553:209-214

Mukhopadhyay P, Mukherjee S, Ahsan K, Bagchi A, Pacher P, Das DK (2010) Restoration of altered micro RNA expression in the ischemic heart with resveratrol. PLoS ONE 5(12):e15705

Ormerod MG, Collins MK, Rodriguez-Tarduchy G, Robertson D (1992) Apoptosis in interleukin-3-dependent haemopoietic cells. Quantification by two flow cytometric methods. J Immunol Methods 153:57-65

Singh K, Xiao L, Remondino A, Sawyer DB, Colucci WS (2001) Adrenergic regulation of cardiac myocyte apoptosis. J Cell Physiol 189:257-265

Sreejit P, Kumar S, Verma RS (2008) An improved protocol for primary culture of cardiomyocyte from neonatal mice. In Vitro Cell Dev Biol Anim 44:45-50

Thandapilly SJ, Wojciechowski P, Behbahani J, Louis XL, Yu L, Juric D, Kopilas MA, Anderson HD, Netticadan T (2010) Resveratrol prevents the development of pathological cardiac hypertrophy and contractile dysfunction in the SHR without lowering blood pressure. Am J Hypertens 23:192-196

Tili E, Michaille JJ, Adair B, Alder H, Limagne E, Taccioli C, Volinia S, Delmas D, Latruffe N, Croce CM (2010a) Resveratrol decreases the levels of miR-155 by upregulating miR-663, a new anti-inflammatory microRNA targeting JunB and JunD. Carcinogenesis 31:1561-1566

Tili E, Michaille JJ, Alder H, Volinia S, Delmas D, Latruffe N, Croce C (2010b) Resveratrol modulates the levels of microRNAs targeting genes encoding tumor-suppressors and effectors of TGFbeta signaling pathway in SW480 cells. Biochem Pharmacol 80:2057-2065

Valentijn AJ, Zouq N, Gilmore AP (2004) Anoikis. Biochem Soc Trans 32(Pt3):421-425

Vermes I, Haanen C, Steffens-Nakken H, Reutelingsperger C (1995) A novel assay for apoptosis. Flow cytometric detection of phosphatidylserine expression on early apoptotic cells using fluorescein labelled Annexin V. J Immunol Methods 184:39-51

Wlodkowic D, Skommer J, Hillier C, Darzynkiewicz Z (2008) Multiparameter detection of apoptosis using red-excitable SYTO probes. Cytometry A 73:563-569 